\title{
PERANCANGAN SISTEM PENDUKUNG KEPUTUSAN PENENTUAN WARGA MISKIN DENGAN METODELOGI AHP DI KECAMATAN SEPATAN KABUPATEN TANGERANG
}

\author{
Muhamad Malik Abdul Azis' ${ }^{1}$ Romat Taufiq ${ }^{2}$ Angga Aditya Permana ${ }^{3}$ Sri Mulyati ${ }^{4}$ \\ Program Studi Informatika \\ Fakultas Teknik Universitas Muhammadiyah Tangerang \\ Jl. Perintis Kemerdekaan I /33 Cikokol Kota Tangerang \\ Email: malikabdulazis786@gmail.com1rohmat.taufiq@yahoo.com² \\ anggaumt@gmail.com³ lilysrimulyati@gmail.com ${ }^{4}$
}

\begin{abstract}
ABSTRAK
Kemiskinan adalah kondisi keterbatasan kemampuan untuk memenuhi kebutuhan hidup secara layak seperti keterbatasan dalam pendapatan, keterampilan, kondisi kesehatan, penguasaan aset ekonomi, ataupun akses informasi, Akan tetapi, Siapa dan bagaimana kelompok warga rentan ini? Apakah mereka miskin, ataukah sangat miskin, Maka dari itu perlu adanya sistem pendukung keputusan untuk menentukan warga miskin dan di buat suatu perancangan sistem pendukung kepututusan menggunakan metodelogi analytical hierarchy proces(AHP). dalam pembangunan perangkat lunak merupakan upaya untuk mengonstruksi sebuah sistem yang memberikan kepuasan (mungkin informal) akan spesifikasi kebutuhan fungsional. Sistem Pendukung Keputusan(SPK) dengan metodelogi Analytical Hierarchy Process(AHP). Di kantor kecamatan sepatan masih menggunakan sistem manual dengan cara melihat file data warga miskin. Berdasarkan penelitian yang telah dilakukan di kantor kecamatan sepatan mengenai salah satu dari program kantor kecamatan sepatan yaitu Warga miskin, dapat diambil kesimpulan bahwa: Dengan adanya perkembangan sistem informasi akan menjawab berbagai masalah khususnya dalam hal keputusan penentuan warga miskin dengan metodelogi analytical hierarchy proces $(A H P)$, Untuk menanggulangi adanya permasalahan dalam penentuan dan mengakuratkan data warga miskin, Agar lebih efektif sehingga tidak memerlukan waktu yang cukup lama, hal ini bertujuan untuk meng efesienkan waktu dan Bagi pihak kecamatan yang ingin menentukan dan mencari data warga miskin menjadi lebih muda.
\end{abstract}

Kata Kunci : Warga miskin, Sistem Pendukung Keputusan(SPK), AHP, Perancangan.

\section{PENDAHULUAN}

Kemiskinan menggambarkan adanya kelangkaan materi atau barang-barang yang diperlukan dalam kehidupan sehari-hari, seperti makanan, pakaian dan perumahan. Kemiskinan dalam artian ini dipahami sebagai kesulitan yang dihadapi orang dalam memperoleh barangbarang yang bersifat kebutuhan dasar, Kemiskinan yang dimaksud diatas adalah kemiskinan absolut, kemiskinan absolut lebih jelasnya adalah suatu kondisi seseorang dengan pendapatan yang tidak cukup untuk memenuhi kebutuhan pokok seperti halnya sandang, pangan dan papan, bahkan mungkin ditambah juga tidak bisa memenuhi kebutuhan kesehatan dan pendidikan. Komputer yang interaktif yang dapat memberikan alternatif solusi bagi pengambil keputusan.

Perkembangan teknologi informasi telah memungkinkan pengambil keputusan dapat dilakukan dengan lebih cepat dan cermat.

Sehingga untuk melakukan pengambilan keputusan dengan lebih cepat, cermat menghindari dan mengurangi subyektifitas keputusan yang dihasilkan diperlukan suatu sistem pendukung keputusan yang bertujuan mempermudah proses verifikasi proposal kegiatan dan penentuan dana kegiatan untuk unit kegiatan mahasiswa melalui proses penentuan kelayakan kegiatan dan alokasi dana yang diberikan untuk melaksanakan 
kegiatan tersebut. Setelah saya melakukan penelitian dan mengumpulkan data di kecamatan sepatan masih banyak yang tergolong warga kurang mampu(miskin), Pihak Kecamatan mengalami kesulitan dalam menentukan siapa saja yang termasuk kategori warga kurang mampu(miskin).

Untuk mengatasi permasalahan yang telah dipaparkan di atas maka penulis melakukan penelitian sebuah sistem yaitu Perancangan Sistem Pendukung Keputusan (SPK) Penentuan Warga Miskin Dengan Metodelogi (AHP).

\section{LANDASAN TEORI \\ a. Perancangan}

Definisi perancangan menurut Rosa dan Shalahudin (2011) dalam Taufiq (2017) Perancangan dalam pembangunan perangkat lunak merupakan upaya untuk mengonstruksi sebuah sistem yang memberikan kepuasan (mungkin informal) akan spesifikasi kebutuhan fungsional, memenuhi target, memenuhi kebutuhan secara implisit atau eksplisit dari segi performasi maupun penggunaan sumber daya, kepuasan batasaan, pada proses desain dari segi biaya, waktu, dan perangkat. Merancang, rancangan merupakan tahap penerjemahan dari keperluan atau data yang telah dianalisis kedalam bentuk yang mudah dimengerti oleh pemakai.

\section{b. Sistem Pendukung Keputusan (SPK)}

Sistem merupakan sesuatu yang sangat dekat, Selalu melekat dan selalu ada dalam kehidupan kita, Baik kita sadari maupun tanpa kita sadari (Taufiq, 2013).

Sistem Pendukung Keputusan atau Decision Support System (DSS) merupakan bagian dari sistem informasi yang biasa digunakan oleh pengambil keputusan dalam mengambil keputusan. Decision Support System diciptakan oleh G. Antony Gorry dan Michael. S. Scott Morton pada tahun 1960-an. Akan tetapi, istilah Sistem Pendukung Keputusan (SPK) itu baru ada pada tahun 1971.

\footnotetext{
Sistem pendukung keputusan merupakan proses pengambilan keputusan dibantu menggunakan komputer untuk membantu pengambil keputusan dengan menggunakan beberapa data dan model tertentu untuk menyelesaikan beberapa masalah yang tidak terstruktur. Keberadaan Sistem pendukung keputusan (SPK) pada perusahaan atau organisasi bukan untuk menggantikan tugas-tugas pengambil keputusan, tetapi merupakan sarana yang membantu bagi mereka dalam pengambilan keputusan. Dengan menggunakan data-data yang diolah menjadi informasi untuk mengambil
}

keputusan dari masalah-masalah semi-terstruktur.

\section{c. Warga Miskin}

Menurut Sujito (2010) Warga miskin adalah kondisi keterbatasan kemampuan untuk memenuhi kebutuhan hidup secara layak seperti keterbatasan dalam pendapatan, keterampilan, kondisi kesehatan, penguasaan aset ekonomi, ataupun akses informasi, dan keadaan di mana terjadi ketidakmampuan untuk memenuhi kebutuhan dasar seperti makanan, pakaian, tempat berlindung, pendidikan, dan kesehatan. Kemiskinan dapat disebabkan oleh kelangkaan alat pemenuh kebutuhan dasar, ataupun sulitnya akses terhadap pendidikan dan pekerjaan.

\section{d. Analytical Hierarchy Process (AHP)}

Proses hirarki adalah suatu model yang memberikan kesempatan bagi perorangan atau kelompok untuk membangun gagasan-gagasan dan mendefinisikan persoalan dengan cara membuat asumsi mereka masing-masing dan memperoleh pemecahan yang diinginkan darinya. Ada dua alasan utama untuk menyatakan suatu tindakan akan lebih baik dibanding tindakan lain. Analytical Hierarchy Process (AHP) merupakan suatu model pendukung keputusan yang dikembangkan oleh Thomas L. Saaty. Model pendukung keputusan ini akan menguraikan masalah multi faktor atau multi kriteria yang kompleks menjadi suatu hirarki, menurut Saaty (1993) dalam anshori (2014), hirarki didefinisikan sebagai suatu representasi dari sebuah permasalahan yang kompleks dalam suatu struktur multi level dimana level pertama adalah tujuan, yang diikuti level faktor, kriteria, sub kriteria, dan seterusnya ke bawah hingga level terakhir dari alternatif.

\section{Seorang decision maker akan memberikan penilaian, mempersepsikan ataupun memperkirakan kemungkinan dari suatu hal/peristiwa yang dihadapi. Penilaian tersebut akan dibentuk kedalam matriks berpasangan pada setiap level hirarki.}

Contoh Pair - Wise Comparison Matrix pada suatu level of hierarchy, yaitu :

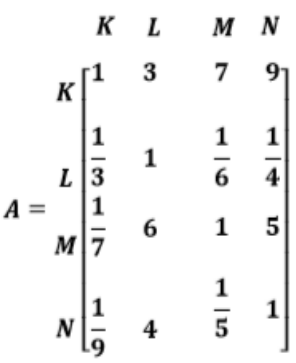


Baris 1 kolom 2 : Jika $\mathrm{K}$ dibandingkan L, maka K sedikit lebih pen ing/cukup penting dari $L$ yaitu sebesar 3 , artinya $\mathrm{K}$ moderat pentingnya dari pada L, dan seterusnya.

Angka 3 bukan berarti bahwa $\mathrm{K}$ tiga kali lebih besar dari $\mathrm{L}$, tetapi $\mathrm{K}$ moderat importance dibandingkan dengan $\mathrm{L}$, sebagai ilustrasi perhatikan matriks resiprokal berikut ini :

$$
\begin{aligned}
& \text { K } \quad L \quad M
\end{aligned}
$$

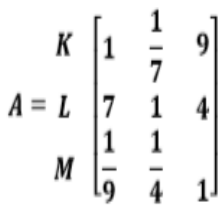

Membacanya/membandingkannya, dari kiri ke kanan. Jika $\mathrm{K}$ dibandingkan dengan $\mathrm{L}$, maka $\mathrm{L}$ very strong importance daripada $\mathrm{K}$ dengan nilai judgement sebesar 7. Dengan demikian pada baris 1 kolom 2 diisi dengan kebalikan dari 7 yakni $\frac{1}{7}$. Artinya, $K$ dibanding $L$ maka $L$ lebih kuat dari $\mathrm{K}$.

Jika $\mathrm{K}$ dibandingkan dengan $\mathrm{M}$, maka $\mathrm{K}$ extreme importance daripada $\mathrm{M}$ dengan nilai judgement sebesar 9. Jadi baris 1 kolom 3 diisi dengan 9 , dan seterusnya.

\section{METODELOGI PENELITIAN}

a. Metode Pengumpulan data

Metode pengumpulan data merupakan teknik atau cara-cara yang dapat digunakan oleh peneliti untuk pengumpulan data. Pengumpulan data sangat diperlukan didalam suatu penelitian. Jenis pengumpulan data sangat banyak, tetapi dalam suatu penelitian teknik pengumpulan data tidak digunakan semua, pengumpulan data dilakukan sesuai dengan kebutuhan penelitian.

\section{Observasi}

Teknik pengumpulan data dimana penyelidikan mengadakan pengamatan secara langsung (tanpa alat) terhadap gejala-gejala subjek yang diselidiki, baik pengamatan itu dilakukan di dalam situasi yang sebenarnya maupun dilakukan di dalam situasi buatan yang khusus diadakan. Dalam hal ini adalah dengan melakukan pengamatan langsung dan mencatat bagai mana proses penentuan warga miskin yang akan dianalisa di Kecamatan Sepatan Kabupaten Tangerang.

\section{Wawancara}

Pengumpulan data melalui tatap muka dan tanya jawab langsung antara pewawan- cara (pengumpul data) dengan responden (sumber data) Berdasarkan hasil wawancara yang dilakukan penulis pada Staft Pemberdayaan Masyarakat Kecamatan Sepatan Kabupaten Tangerag maka penulis mendapatkan informasi terkait yang dibutuhkan.

\section{Dokumentasi}

Menggunakan data tertulis yaitu kegiatan memperoleh data dengan menganalisis dan memepelajari dokumen atau catatan yang ada. Ada beberapa dokumen Keacamatan yang dapat mendukung dalam penelitian ini misalkan dokumen Kecamatan meliputi sejarah, Visi dan Misi Kecamatan Sepatan Kabupaten Tangērang, Struktur organisasi dan deskripsi tugas, beserta dokumen-dokumen pendukung lainnya.

\section{b. Metode Pengembangan Sistem}

Metode pengembangan yang digunakan penulis dalam penelitian ini adalah metode waterfall atau juga disebut model air terjun pemilihan model waterfall dikarenkan model ini menyediakan pendekatan alur hidup pe- rangkat lunak secara terurut mulai dari analisis, desain, pengkodean, pengujian.

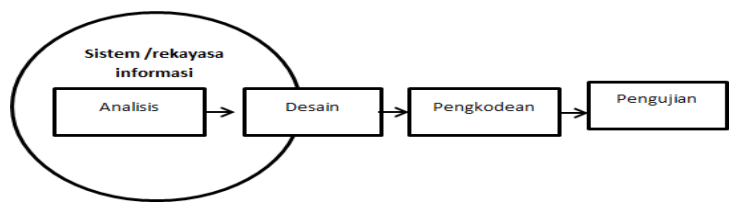

Gambar 3.1 Ilustrasi model waterfall Sumber: Taufiq (2017)

\section{Analisis}

Setelah menentukan bidang penelitian yang dikaji dan melakukan pengumpulan data terkait pada sistem pendukung keputusan dengan menggunakan metode AHP dalam menentukan penentuan warga miskin, maka tahap selanjutnya adalah menganalisa sistem. Analisa yang dilakukan dengan menerapkan metode AHP. Dalam analisa sistem tersebut terdapat beberapa subsistem, diantanya adalah sebagai berikut:

\section{a. Analisa Subsistem Manajemen Data}

Subsistem data merupakan analisa terhadap kebutuhan data yang akan digunakan untuk membangun sistem dalam 
penentuan warga miskin. Data-data tersebut terdiri atas masukan data dan keluaran data.

\section{b. Analisa Subsistem Manajemen Model}

Pada tahapan ini digunakan model perankingan alternatif terbaik dari beberapa alternatif. Model yang digunakan menggunakan metode Analitycal Hierarchy Process (AHP) yang merupakan basis dari proses pengambilan keputusan untuk menentukan alternatif terbaik. Proses langkah-langkah metode Analitycal Hierarchy Process (AHP) dapat digambarkan dalam bentuk Unified Modeling Language (UML) yang mendeskripsikan proses perhitungan metode AHP yang terjadi dimulai dari awal perhitungan hingga selesai.

\section{c. Analisa Subsistem Manajemen Dialog}

Subsistem manajemen dialog merupakan analisa terhadap kebutuhan sistem yang mengacu pada perancangan struktur menu dan perancangan antar muka yang akan di implementasikan kedalam sistem pendukung keputusan penentuan warga miskin.

\section{Desain}

Tahap desain dilakukan agar mudah merepresentasikan antarmuka dan dapat diimplementasiakan menjadi program guna mempermudah dalam coding. Tahap desain ini adalah melakukan perancangan yang berupa permodelan untuk mewakili sistem yang berjalan saat ini pada Kecamatan Sepatan Kabupaten Tangerang, Permodelan yang digunakan adalah UML (unified modeling language) yang sering digunakan dalam menggambarkan arsitektur.

\section{Pengkodean}

Merupakan tahap penerapan dari proses analisis dan perancangan sistem pada bab sebelumnya dimana data akan diproses kedalam perangkat lunak sistem (source code) apakah sistem dapat berjalan sesuai dengan kebutuhan. Untuk mengimplementasikan sistem pendukung keputusan penentuan warga miskin maka dibutuhkan perangkat pendukung, perangkat tersebut berupa perangkat lunak dan perangkat keras.

\section{Pengujian}

Melakukan pengujian terhadap rancangan sistem secara keseluruhan dalam sistem penentuan warga miskin agar berjalan dengan baik. pengujian dilakuakan agar dapat dijalankan sesuai dengan fungsinya dan diharapkan setiap subsitem dapat berjalan sesuai dengan yang diinginkan. Pengujian dilakukan sesuai dengan modul yang dibahas. pengujian di representasikan dalam bentuk tabel-tabel sesuai fungsi-fungsi dari sistem yang telah di uji dan diguanakan sesuai peruntukannya.

\section{ANALISIS DAN PEMBAHASAN}

\section{a. Analisa Kebutuhan}

Pada penelitian ini diperlukan komponenkomponen pendukung dalam membangun program aplikasi yang akan dibuat. Komponen-komponen tersebut antara lain SDM (sumber daya manusia), kebutuhan user, sistem pendukung berupa perangkat keras dan perangkat lunak komputer, dan kebutuhan data serta informasi.

\section{b. Analisa Analytical Hierarchy Process (AHP)}

$\begin{array}{crr}\text { Dalam analisa Analytical } & \text { Hierarchy } \\ \text { Process(AHP), } & \text { dilakukan proses }\end{array}$ perhitungan matrix perbandingan kriteria. Setiap elemen yang terdapat dalam hirarki harus diketahui bobot relatifnya satu sama lain. Tujuan untuk mengetahui tingkat kepentingan pihak - pihak yang berkepentingan dalam permasalahan terhadap kriteria dan struktur hirarki atau sistem secara keseluruhan. Langkah pertama dilakukan dalam menentukan prioritas kriteria adalah menyusun perbandingan berpasangan, yaitu membandingkan dalam bentuk berpasangan seluruh kriteria untuk setiap sub sistem hirarki.

\section{a. Kriteria penentuan warga miskin}

$$
\begin{aligned}
& \text { Kriteria yang di gunakan dalam } \\
& \text { proses penentuan warga miskin } \\
& \text { sebanyak } 4 \text { kriteria, Tabel kriteria dan } \\
& \text { sukriteria yang digunakan sebagai } \\
& \text { berikut: }
\end{aligned}
$$

Tabel 4.1 Kriteria dan subkriteria 


\begin{tabular}{|c|c|}
\hline KRITERIA & SUBKRITERIA \\
\hline PEKERJAAN & $\begin{array}{l}\text { 1. Apakah warga } \\
\text { memiliki } \\
\text { pekerjaan. } \\
\text { 2. Apakah warga } \\
\text { tidak bekerja }\end{array}$ \\
\hline PENGHASILAN & $\begin{array}{ll}\text { 1. Apakah di atas } \\
600.000 \\
\text { perbulan, } \\
\text { 2. Apakah di } \\
\text { bawah } 600.000 \\
\text { perbulan. }\end{array}$ \\
\hline TANGGUNGAN & $\begin{array}{l}\text { 1. Berapah } \\
\text { tanggungan } \\
\text { yang dimiliki, } \\
\text { melebihi } 2 \text { anak } \\
\text { atau kurang dari } \\
2 \text { anak. }\end{array}$ \\
\hline \multirow[t]{2}{*}{ RUMAH: } & $\begin{array}{l}\text { 1. Apakah rumah } \\
\text { layak untuk di } \\
\text { tempati }\end{array}$ \\
\hline & $\begin{array}{l}\text { 2. Apakah rumah } \\
\text { tidak layak untuk } \\
\text { di tempati }\end{array}$ \\
\hline
\end{tabular}

b. Memberikan Nilai Perbandingan

Nilai yang diberikan pada setiap kriteria dan sub kriteria untuk selanjutnya diproses dengan menggunakan metode Analytical Hierarchy Process(AHP) adalah sebagai berikut, untuk menentukan hasil proses perhitungan menggunakan software microsoft office excel 2010.

\section{Perbandingan dan Normalisasi Kriteria}

\begin{tabular}{|c|c|c|c|c|}
\hline \multicolumn{5}{|c|}{ PERBANDINGAN KRITERIA } \\
\hline & Tanggungan & Pekerjaan & Penghasilan & Rumah \\
\hline Tanggungan & 1.00 & 3.00 & 5.00 & 7.00 \\
\hline Pekerjaan & 0.33 & 1.00 & 2.00 & 5.00 \\
\hline Penghasilan & 0.20 & 0.50 & 1.00 & 5.00 \\
\hline Rumah & 0.14 & 0.20 & 0.20 & 1.00 \\
\hline Jumlah & 1.68 & 4.70 & 8.20 & 18.00 \\
\hline
\end{tabular}

Setelah melakukan pembobotan tiap kriteria dan mengetahui nilai dan kriteria mana yg paling penting, kemudian melakukan normalisasi kriteria seperti contoh tabel dibawah ini:

\begin{tabular}{|c|c|c|c|c|c|c|}
\hline \multicolumn{7}{|c|}{ NORMALISASI } \\
\hline & Tanggungan & Pekerjaan & Penghasilan & Rumah & Jumlah & $\begin{array}{c}\text { Priority } \\
\text { vektor }\end{array}$ \\
\hline Tanggungan & 0.60 & 0.64 & 0.61 & 0.39 & 2.23 & 0.56 \\
\hline Pekerjaan & 0.20 & 0.21 & 0.24 & 0.28 & 0.93 & 0.23 \\
\hline Penghasilan & 0.12 & 0.11 & 0.12 & 0.28 & 0.63 & 0.16 \\
\hline Rumah & 0.09 & 0.04 & 0.02 & 0.06 & 0.21 & 0.05 \\
\hline Jumlah & 1.00 & 1.00 & 1.00 & 1.00 & 4.00 & 1.00 \\
\hline
\end{tabular}

Jika sudah di normalisasikan kemudian mencari nilai lamda, $\mathrm{Cl}, \mathrm{RI}$, dan $\mathrm{CR}$ :

\begin{tabular}{|c|c|c|c|}
\hline MMAX & $\mathrm{Cl}$ & $\mathrm{RI}$ & $\mathrm{CR}$ \\
\hline 4.25 & 0.08 & 0.90 & 0.09 \\
\hline
\end{tabular}

Setelah memasukkan nilai perbandingan diatas dengan menggunakan microsoft office excel 2010 maka secara otomatis bisa diketahui nilai Rasio Keterangan:

$$
\begin{aligned}
& \mathrm{Cl}=\text { Consistency Index } \\
& \mathrm{RI}=\text { Random Index } \\
& \mathrm{CR}=\text { Consistency Ratio }
\end{aligned}
$$

$\mathrm{CR}<\quad 0,1$ maka nilai perbandingan berpasangan pada matriks kriteria yang diberikan konsistensi. Jika $C R \geq 0,1$ maka nilai perbandingan berpasangan pada matriks Kriteria yang diberikan tidak konsisten. Sehingga jika tidak konsisten, maka pengisian nilai - nilai pada matriks berpasangan pada unsur kriteria maupun

\begin{tabular}{|c|c|c|c|c|c|c|}
\hline \multicolumn{7}{|c|}{ PERBANDINGAN SUBKRITERIA TANGGUNGAN } \\
\hline & \multicolumn{3}{|c|}{ Lebih 2 anak } & \multicolumn{3}{|c|}{ Kurang dari 2 anak } \\
\hline \multicolumn{2}{|c|}{ Lebih 2 anak } & \multicolumn{2}{|c|}{1.00} & \multicolumn{3}{|c|}{9.00} \\
\hline \multicolumn{2}{|c|}{ Kurang dari 2 anak } & \multicolumn{2}{|r|}{0.11} & \multicolumn{3}{|c|}{1.00} \\
\hline \multicolumn{2}{|c|}{ Jumlah } & \multicolumn{2}{|r|}{1.11} & \multicolumn{3}{|c|}{10.00} \\
\hline \multicolumn{7}{|c|}{ NORMALISASI TANGGUNGAN } \\
\hline & Lebih 2 & anak & Kurang dari $2 \mathrm{a}$ & aak & Jumlah & Priority veltor \\
\hline Lebih 2 anak & 0.9 & 0 & 0.90 & & 1.80 & 0.90 \\
\hline Kurang dari 2 anak & 0.1 & 10 & 0.10 & & 0.20 & 0.10 \\
\hline Jumlah & 1.0 & 0 & 1.00 & & 2.00 & \\
\hline
\end{tabular}
alternatif harus diulang.

\section{Perbandungan dan Normalisasi Kriteria}




\begin{tabular}{|l|c|c|}
\hline \multicolumn{3}{|c|}{ PERBANDINGAN SUBKRITERIA PEKERJAAN } \\
\hline & Tidak bekerja & Bekerja \\
\hline Tidak bekerja & 1.00 & 9.00 \\
\hline Bekerja & 0.11 & 1.00 \\
\hline Jumlah & 1.11 & 10.00 \\
\hline
\end{tabular}

\begin{tabular}{|l|c|c|c|c|}
\hline \multicolumn{5}{|c|}{ NORMALSASI PEKERIAAN } \\
\hline & Tidak bekerja & Bekerja & Jumlah & Priority vektor \\
\hline Tidak bekerja & 0.90 & 0.90 & 1.80 & 0.90 \\
\hline Bekerja & 0.10 & 0.10 & 0.20 & 0.10 \\
\hline Jumlah & 1.00 & 1.00 & 2.00 & \\
\hline
\end{tabular}

\begin{tabular}{|l|c|c|}
\hline \multicolumn{3}{|c|}{ PERBANDINGAN SUBKRITERIA PENGHASILAN } \\
\hline & Dibawah 600.000 & Di atas 600.000 \\
\hline Dibawah 600.000 & 1.00 & 9.00 \\
\hline Di atas 600.000 & 0.11 & 1.00 \\
\hline Jumlah & 1.11 & 10.00 \\
\hline
\end{tabular}

\begin{tabular}{|l|c|c|c|c|}
\hline \multicolumn{5}{|c|}{ NORMALISASI PENGHASILAN } \\
\hline & $\begin{array}{c}\text { Dibawah } \\
600.000\end{array}$ & $\begin{array}{c}\text { Di atas } \\
600.000\end{array}$ & Jumlah & $\begin{array}{l}\text { Priority } \\
\text { vektor }\end{array}$ \\
\hline Di bawah 500.000 & 0.90 & 0.90 & 1.80 & 0.90 \\
\hline Di atas 500.000 & 0.10 & 0.10 & 0.20 & 0.10 \\
\hline Jumlah & 1.00 & 1.00 & 2.00 & \\
\hline
\end{tabular}

\begin{tabular}{|l|c|c|}
\hline \multicolumn{3}{|c|}{ PERBANDINGAN SUBKRITERIA RUMAH } \\
\hline & Tidak Layak & Layak \\
\hline Tidak Layak & 1.00 & 9.00 \\
\hline Layak & 0.11 & 1.00 \\
\hline Jumlah & 1.11 & 10.00 \\
\hline
\end{tabular}

\begin{tabular}{|l|c|c|c|c|}
\hline \multicolumn{5}{|c|}{ NORMALSASI RUMAH } \\
\hline & Tidak Layak & Layak & Jumlah & Priority Vektor \\
\hline Tidak layak & 0.90 & 0.90 & 1.80 & 0.90 \\
\hline Layak & 0.10 & 0.10 & 0.20 & 0.10 \\
\hline Jumlah & 1.00 & 1.00 & 2.00 & \\
\hline
\end{tabular}

Setelah nilai sudah diketahui dan sudah di uji consistensinya, Maka untuk mengetahui apakah warga tersebut miskin atau tidak dengan cara menjumlahkan nilai priority vector kriteria dan nilai priority subkriteria (pv), Dengan rumus:

\section{$\left(\mathrm{Sk} 1{ }^{*} \mathrm{~K} 1+\mathrm{Sk} 2{ }^{*} \mathrm{~K} 2+\mathrm{Sk} 3^{*} \mathrm{~K} 3+\mathrm{Sk} 4^{*} \mathrm{~K} 4=\right)$}

Jika nilai hasil total <dari 0.5 warga tersebut tidak miskin, dan jika nilai hasil total $>0.5$ maka warga tersebut miskin.

\section{c. Perancangan Alur Proses Sistem}

Tahap perancangan sistem dimulai setelah tahap analisa selesai dan didefinisikan secara jelas. Di dalam tahap ini akan dijelaskan lebih rinci lagi dengan didasarkan pada tahapan sebelumnya, kemudian detail aliran proses dari software yang akan dibangun. Hasil dari tahap perancangan dapat diterapkan menjadi prosedur-prosedur dengan alat bantu bahasa pemrograman yang ada.

Perancangan sistem yang penulis gunakan adalah model UML (Unified Modelling Language). Model ini terdiri dari beberapa diagram, namun penulis menggunakan 1 diagram perancangan, yaitu usecase diagram,

\section{UseCase Diagram :}

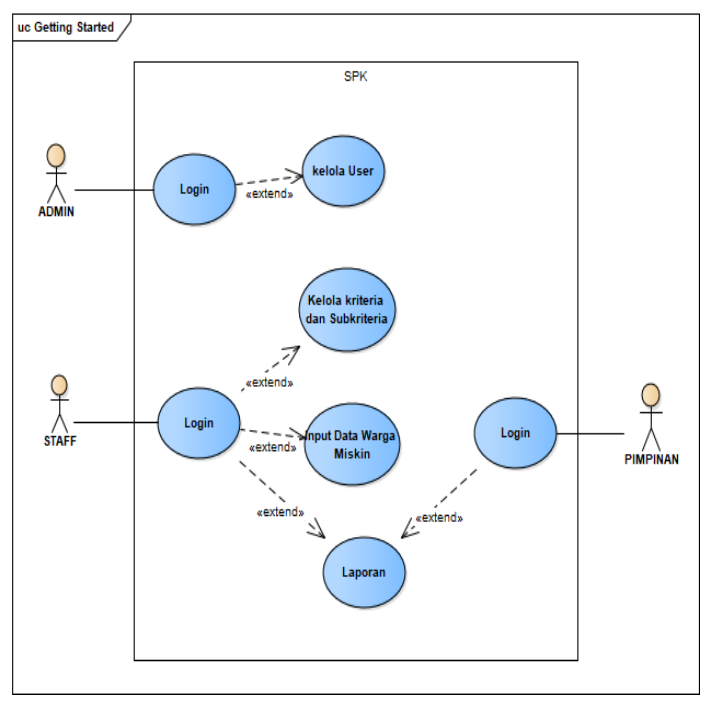

Gambar 2. Usecase diagram

\section{c. Implementasi Sistem}

Implementasi yang dilakukan oleh penulis adalah merealisasikan kelas-kelas yang dibentuk pada tahap desain ke dalam suatu kode bahasa pemrograman, sehingga dapat menghasilkan 
suatu perangkat lunak yang nyata dan dapat digunakan. Berikut adalah tampilan-tampilan dari sistem pendukung keputusan penentuan warga miskin :

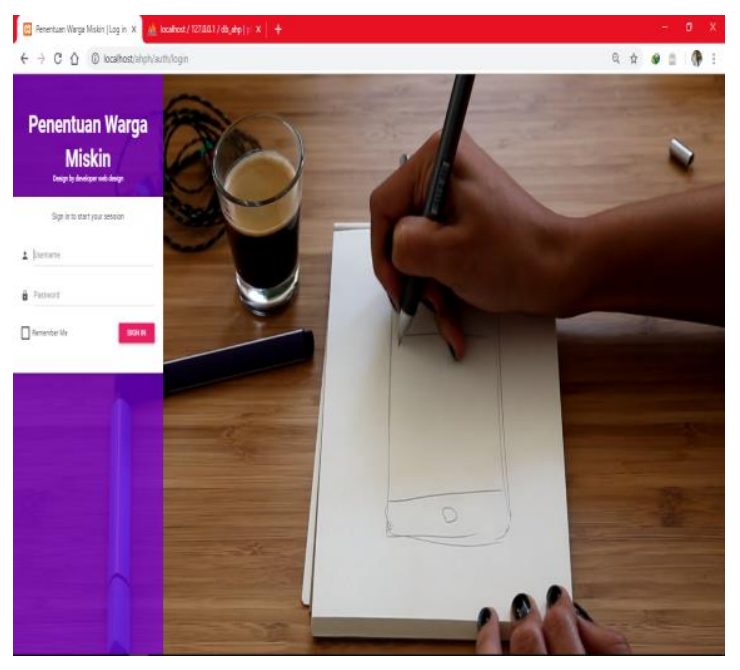

Gambar 4.3 Tampilan login

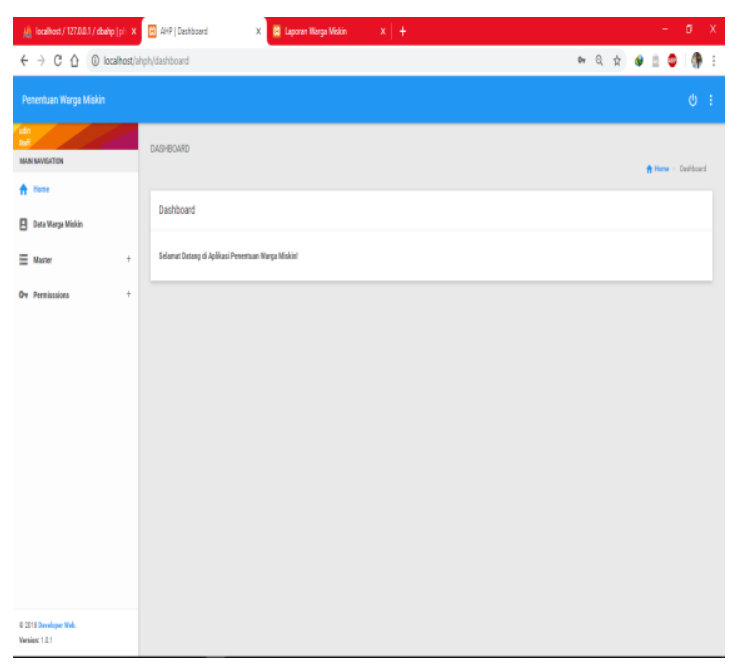

Gambar 4.4 Tampilan Dashboard

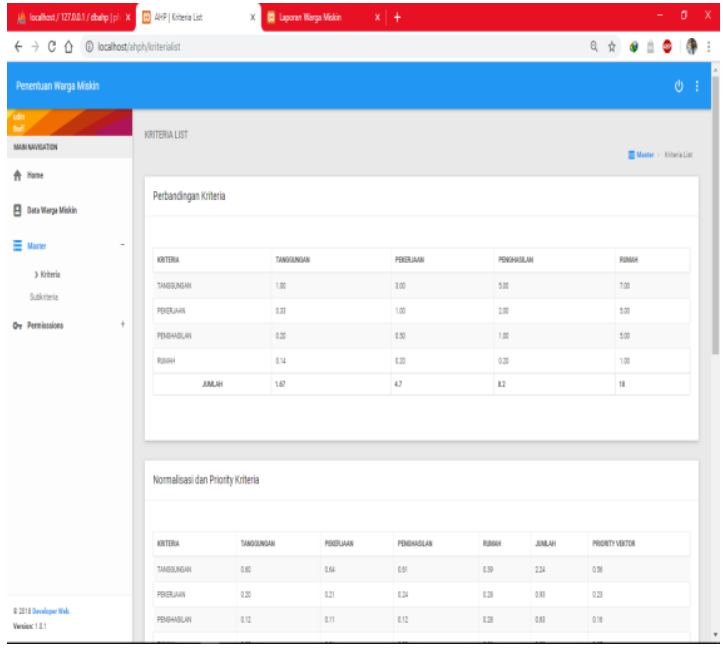

Gambar 4.5 Form tabel kriteria

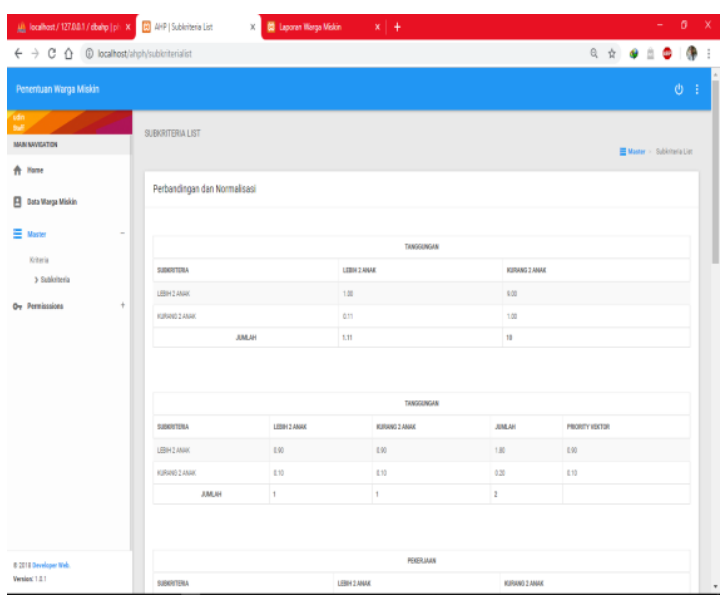

Gambar 4.6 Form tabel subkriteria

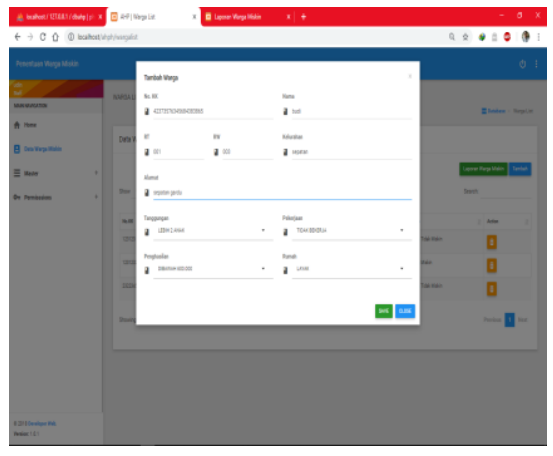

Gambar 4.7 Form perhitungan AHP 


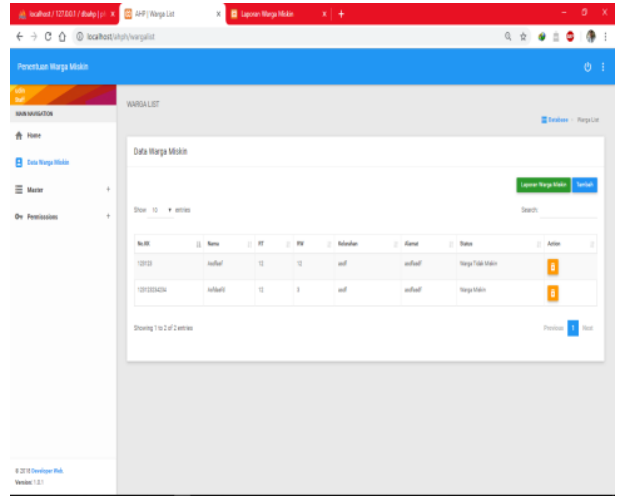

Gambar 4.8 Form data warga miskin

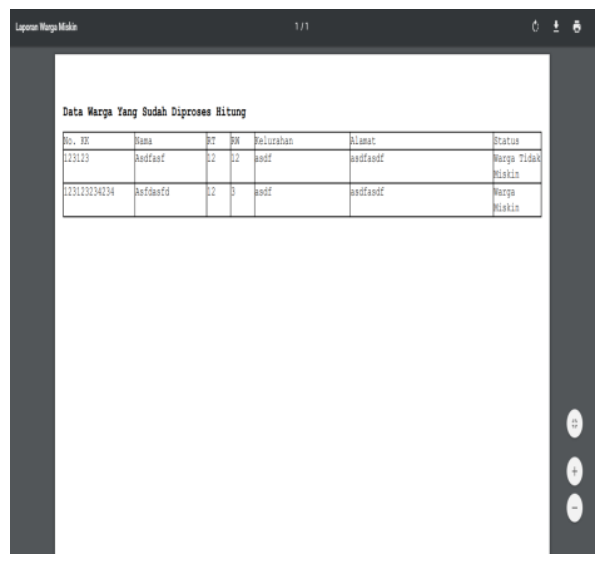

Gambar 4.9 Hasil/Laporan

\section{KESIMPULAN}

Berdasarkan penelitian yang telah dilakukan di kantor kecamatan sepatan mengenai salah satu dari program kantor kecamatan sepatan yaitu Warga miskin, Tentang penentuan warga miskin maka penulis dapat menarik beberapa kesimpulan sebagai berikut :

a. Dengan adanya sistem pendukung keputusan akan menjawab berbagai masalah khususnya dalam hal keputusan penentuan warga miskin dengan metodelogi analytic hierarchy proces(AHP).

b. Untuk menanggulangi adanya permasalahan dalam penentuan dan mengakuratkan data warga miskin, Agar lebih efektif sehingga tidak memerlukan waktu yang cukup lama, hal ini bertujuan untuk meng efesienkan waktu.

c. Bagi pihak kecamatan yang ingin menentukan dan mencari data warga miskin menjadi lebih mudah.

\section{REFERENSI}

[1] Rossa dan Shalahuddin, M. (2014). Rekayasa Perangkat Lunak. Bandung: Penerbit Informatika.

[1] Rohmat Taufiq, (2013), Sistem Informasi Manajemen, Yoyakarta:

Penerbit Graha IImu.

[2] Erna, 2015, Penerapan Metode Analytical Hierarchy Process ( Ahp ) Pada Sistem Pendukung Keputusan Pemilihan Mahasiswa Berprestasi Menggunakan Framework Laravel, Jurnal SCRIPT Vol. 3 No. 1 Desember 2015, pp. 49-57.

[2] R Taufiq, 2017, Perancangan Sistem Pendukung Keputusan Penerimaan Beasiswa Menggunakan Metode SAW Pada SMP Yuppentek 1 Legok, Vol. 6 No.2, Desember 2017,

$\mathrm{pp}$. 1-9.

[2] Wahyuni, 2014, Sistem Pendukung Keputusan Untuk Penilaian Kinerja Pegawai Menggunakan Metode Analytical Hierarchy Process (Ahp), Jurnal Sistem Informasi Vol- 1 No.1

2014, pp. 33-37.

[5]. Nasikun Dalam Trijono, 1995: 13,-Hidup Dalam Kemiskinan Seringkali Juga Berarti Akses Yang Rendah Terhadap Berbagai Ragam Sumber Daya Dan Aset Produktif .https://www.slideshare.net/EnengNs/kemis kinan-dan-kesenjangan-pendapatan70463777.

[5] Sujito, 2010: 4,-Kaum Miskin Tidak Memiliki Ruang, Sekaligus Lemah Dalam Kemampuan Menegosiasikan Haknya Demi Membela Diri Agar Mendapatkan keadilan-

http://abstrak.ta.uns.ac.id/wisuda/upload/D 0312041_bab1.pdf. 